\title{
Detection of human papillomavirus DNA in urinary bladder carcinoma by in situ hybridisation
}

\author{
Carmela De Gaetani, Giovanni Ferrari, Elisa Righi, Stefania Bettelli, Mario Migaldi,
} Paolo Ferrari, Gian Paolo Trentini

\begin{abstract}
Aims-To investigate the sensitivity of an in situ hybridisation system to detect human papillomavirus (HPV) infection in transitional cell bladder cancer and to evaluate the advantages of analysing multiple biopsies; to examine the correlation between HPV tumour infection detected by in situ hybridisation and the presence of serum anti-HPV antibodies detected by enzyme linked immunosorbent assay (ELISA); and to relate the presence of viral infection to grade, stage, and follow up in cases of bladder cancer.
\end{abstract}

Methods-The in situ hybridisation technique was used with broad spectrum and type specific $(6 / 11,16 / 18,31 / 33 / 35)$ probes against HPV DNA in formalin fixed, paraffin embedded tissues from 43 cases of bladder cancer. The results were analysed for the presence and type of papillomavirus and correlated with clinicopathological variables.

Results-The presence of HPV DNA was identified by the in situ hybridisation technique in 17 of 43 cases of bladder cancer; 12 of these were serum antibody positive and 10 had had multiple biopsies. Fifteen of the cases that were negative for HPV DNA by in situ hybridisation had positive serum serology when tested by ELISA. In 14 cases, the HPV was either types $16 / 18$ or types $31 / 33 / 35$, both of which carry high oncogenic risk. The stage $(p<0.05)$ and grade (NS) of the tumour and the outcome on follow up $(p<0.05)$ were correlated with the presence of HPV infection.

Department of Morphological Sciences and Legal Medicine, Section of Anatomic Pathology, University of Modena, via del Pozzo 71, 41100 Modena, Italy

C De Gaetani

E Righi

S Bettelli

$M$ Migaldi

G P Trentini

Division of Urology, AUSL Modena,

Modena, Italy

G Ferrari

P Ferrari

Correspondence to: Dr Righi.

Accepted for publication 24 August 1998 -ELISA is not useful in fying patients with HPV positive bladder cancer, but the use of several probes and multiple biopsies increases the detection rate of HPV in neoplastic tissues. The association between tumour virus infection and high grade/high stage tumours and worse outcome suggests that HPV infection of neoplastic tissue has a negative effect on the behaviour and evolution of transitional cell bladder carcinoma. (f Clin Pathol 1999;52:103-106)

Keywords: human papillomavirus; in situ hybridisation; bladder carcinoma

The increasing incidence of bladder carcinoma observed in the past three decades has stimulated research into the identification of possible aetiological agents. The possible role of viruses in this respect is still highly controversial. ${ }^{1-4}$

The significant association between human papillomavirus (HPV) infection and genital cancers in both sexes has prompted attempts to identify HPV in bladder cancers as well as in various benign lesions of the urinary tract. ${ }^{5} \mathrm{At}$ present more than 90 distinct types of HPV have been recognised ${ }^{67}$ and more than 35 of these have shown specific tropism for the male and female genitourinary tract, ensuring an easy mode of transmission between these natural reservoirs. ${ }^{3}$

However, even in the most up to date reports there is no agreement about the occurrence of HPV in bladder carcinoma, the percentage of positive cases ranging between $0 \%{ }^{8-11}$ to $80 \%$. $^{2}$ The choice of material and the different techniques performed seem to influence the number of false positive and false negative results - that is, the use of single or multiple tumour fragments, fresh or fixed and paraffin embedded material, the number of virus genotypes sought, contamination by plasmid DNA or polymerase chain reaction (PCR) products, and the use of high or low sensitivity techniques (Southern blot, PCR, or in situ hybridisation).

It was against this background that we set out to determine whether the use of multiple biopsies and multiple probes in an in situ hybridisation system could increase the detection rate of HPV positive cases. At the same time, we wished to examine the possible relation between circulating anti-HPV antibody detected by an immunoenzymatic assay and the presence of HPV positive bladder cancer, identified by in situ hybridisation of HPV DNA in cancer tissues.

Our final aim was to make a preliminary evaluation of the possible correlation between the presence of HPV DNA and clinicopathological indices such as grade, stage, and evolution of the neoplastic disease.

\section{Methods}

Between 1995 and 1997, we carried out enzyme linked immunosorbent assays (ELISA) for serum antibodies against human and bovine papillomaviruses in 43 patients with transitional cell papillary carcinoma of the urinary bladder at the time of diagnosis ( 38 males, five females, age range 36 to 85 years, mean (SD) age 66.3 (19.8) years). Twenty seven of these were serum antibody positive, 13 were serum negative, and three were classified as uncertain, with antibody titres that were barely above the cut off point. The 
Table 1 Clinical details and follow up data on 43 cases of bladder carcinoma

\begin{tabular}{|c|c|c|c|c|c|c|}
\hline \multirow{2}{*}{$\begin{array}{l}\text { Sex } \\
\text { Male } 38(88.4 \%)\end{array}$} & \multicolumn{2}{|c|}{ Grade } & \multicolumn{2}{|l|}{ Stage } & \multicolumn{2}{|c|}{ Follow up* } \\
\hline & I & $3(6.9 \%)$ & Ta-T1 & $21(48.8 \%)$ & $\mathrm{ADF}$ & 23 \\
\hline Female $5(11.6 \%)$ & II & $24(55.8 \%)$ & $\mathrm{T} 2-\mathrm{T} 4$ & $22(51.2 \%)$ & $\mathrm{AD}$ & 4 \\
\hline & III & $16(37.3 \%)$ & & & DD & 15 \\
\hline
\end{tabular}

Mean (SD) age 62.1 (1.1) years; median follow up 72 months. *One patient lost to follow up. $\mathrm{AD}$, alive with disease; $\mathrm{ADF}$, alive and disease-free; $\mathrm{DD}$, died of disease.

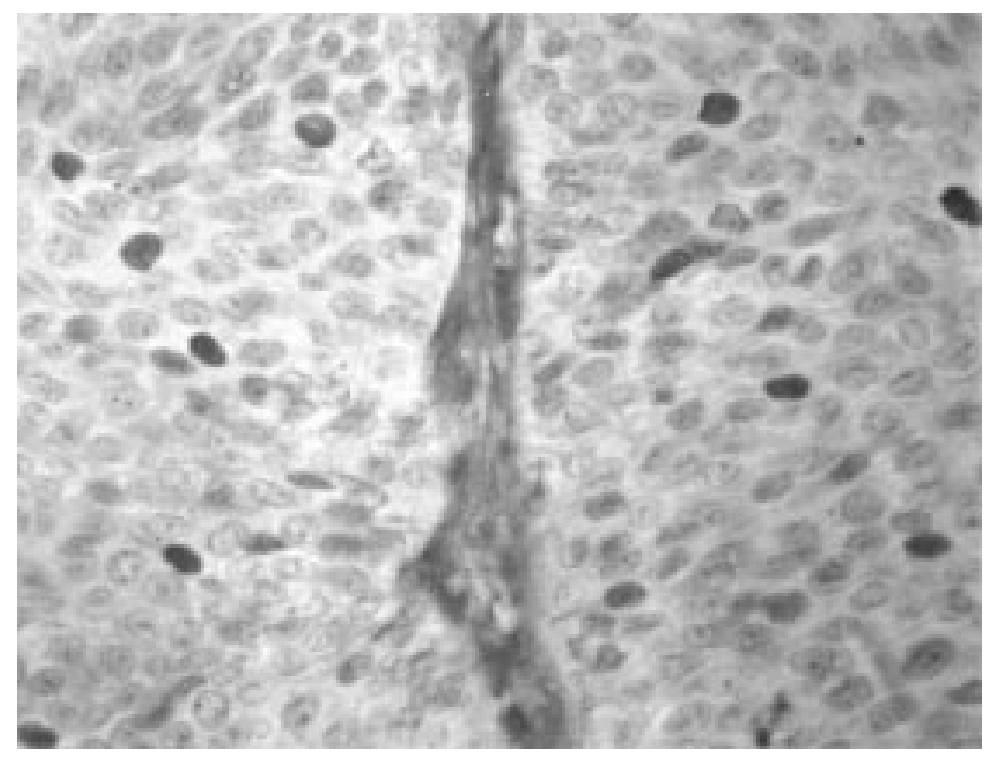

Figure 1 In situ hybridisation with 31/33/35 type specific HPV DNA probe of a grade II papillary carcinoma of the bladder. The staining reaction (dark blue) identifies the HPV positive nuclei $(\times 292)$.

distinctive clinicopathological features of the tumours at diagnosis and the follow up data are given in table 1 .

In 21 patients, a single tumour sample was available for histopathological study, as these patients either had a relapse-free outcome after transurethral resection or had radical cystectomy as the treatment of first choice. In the remaining 22 patients, 88 consecutive tumour samples (two to nine per patient) were collected either from the primitive tumour or from recurrences during follow up. Recurrences were treated by transurethral resection or radical cystectomy when staging procedures showed tumour progression with muscular infiltration.

Tumour biopsy specimens were fixed in 10\% buffered formalin, embedded in paraffin, and diagnosed on haematoxylin-eosin stained sections.

The presence of HPV DNA in neoplastic tissue was investigated on $6 \mu \mathrm{m}$ thick paraffin sections by means of a non-isotopic in situ

Table 2 Correlation between anti-HPV serum antibodies and HPV DNA infection in bladder carcinoma

\begin{tabular}{|c|c|c|c|c|c|}
\hline \multirow[b]{3}{*}{$H P V A b$} & \multicolumn{4}{|c|}{ In situ hybridisation } & \multirow[b]{3}{*}{ Total } \\
\hline & \multicolumn{2}{|c|}{ Omniprobe } & \multicolumn{2}{|c|}{ Kit K602 } & \\
\hline & Positive & Negative & Positive & Negative & \\
\hline Positive & 9 & 18 & $12(3)$ & 15 & 27 \\
\hline Negative & $3(1)$ & 10 & $3(1)$ & 10 & 13 \\
\hline Uncertain & 0 & 3 & $1(1)$ & 2 & 3 \\
\hline Total & $12(1)$ & 31 & $16(5)$ & 27 & 43 \\
\hline
\end{tabular}

$\mathrm{Ab}$, antibodies; HPV, human papillomavirus. Number of cases positive to only one probe given in parentheses. hybridisation technique. Two generic, broad spectrum biotinylated HPV DNA probes (HPV staining kit K602, Dako, and HPVOmniprobe, Digene) raised against HPV DNA types $6,11,16,18,30,31,33,35,45,51$, and 52 and types $6,11,16,18,31,33,35,42,43$, $44,45,51$, and 56, respectively, were employed. Biopsy specimens which stained positively by either of these two generic probes were also tested for $6 / 11,16 / 18$, and 31/33/35 type specific HPV DNAs (Viratype, Digene) (fig 1).

In situ hybridisation procedures were performed according to the manufacturer's instructions. Briefly, tissue sections were first dewaxed in xylene, hydrated, and digested in preheated pepsin- $\mathrm{HCl}$ at $37 \%$ for seven minutes. After dehydration, the hybridisation probes were pipetted on the sections, which were placed under coverslips and denatured at $95^{\circ} \mathrm{C}$ for five minutes. Hybridisation was carried out in a humidified chamber at $37^{\circ} \mathrm{C}$ for 60 minutes, after which each section was rinsed twice in Tris buffered saline for three minutes at room temperature, and then in preheated stringent wash solution included in the test kit at $48^{\circ} \mathrm{C}$ for 30 minutes. Finally, the sections were incubated first with streptavidin-AP reagent at room temperature for 20 minutes and then with chromogen solution (BCIP/ NBT) at room temperature in the dark for 60 minutes. Sections of known positivity and negativity were used as internal controls.

STATISTICS

The SPSS/PC+ program package was used for basic statistical calculations. Comparison and significant differences between groups were made using the $\chi^{2}$ test and Fisher's exact test where appropriate. Probability $(\mathrm{p})$ values less than 0.05 were considered significant.

\section{Results}

Seventeen of the 43 patients (39.5\%) with papillary carcinoma of the bladder tested for HPV DNA in the neoplastic tissue were found to be positive by in situ hybridisation with broad spectrum HPV DNA probes. Of these, 11 were positive for both broad spectrum probes, while six were positive for a single probe, in five cases the K602 probe.

Of 17 cancer positive patients, 12 were serum antibody positive, four were serum antibody negative, and one was serologically uncertain (table 2).

Table 3 shows that seven of the 17 HPV DNA positive patients had only a single biopsy, while 10 had multiple biopsies. Multiple biopsies thus appeared to increase the proportion of positive cases detected. Further support for this observation came from the finding that in only one of these 10 cases was HPV DNA detected in all five consecutive samples, while the remaining nine cases there were alternating positive and negative biopsies.

The use of HPV DNA type-specific probes confirmed the broad spectrum probe findings, with positive results in all cases except two; these two were, however, positive for both the broad spectrum probes. Ten cases were found to contain HPV 31/33/35, two in association 
Table 3 In situ hybridisation HPV DNA positivity in single and multiple biopsies

\begin{tabular}{llcl}
\hline & $\begin{array}{l}\text { Patients } \\
n(\%)\end{array}$ & $\begin{array}{l}\text { Single biopsy } \\
n(\%)\end{array}$ & $\begin{array}{l}\text { Multiple biopsies } \\
(\%)\end{array}$ \\
\hline Positive & $17(40)$ & $7(41)$ & $10(59)^{\star}$ \\
Negative & $26(60)$ & $14(54)$ & $12(46)$ \\
Total & $43(100)$ & $21(49)$ & $22(51)$ \\
\hline
\end{tabular}

HPV, human papillomavirus.

*In one case only, virus search was positive in five consecutive biopsies; in the remaining nine cases, some samples were positive and some negative.

Table 4 Results of in situ hybridisation with type specific probes in 17 cases positive with broad spectrum probes

\begin{tabular}{llll}
\hline Case No & $6 / 11$ & $16 / 18$ & $31 / 33 / 35$ \\
\hline 1 & + & - & - \\
2 & + & + & - \\
3 & + & - & + \\
4 & - & + & - \\
5 & - & + & - \\
6 & - & + & - \\
7 & - & + & + \\
8 & - & + & + \\
9 & - & - & + \\
10 & - & - & + \\
11 & - & - & + \\
12 & - & - & + \\
13 & - & - & + \\
14 & - & - & + \\
15 & - & - & + \\
16 & - & - & - \\
17 & - & - & - \\
Total 17 (11) & $3(1)$ & $6(3)$ & $10(7)$ \\
\hline
\end{tabular}

Numbers of cases positive to only one probe given in parentheses.

with $16 / 18$, and one in association with $6 / 11$. In contrast, only four cases contained HPV 16/18, one in association with $6 / 11$, while only one case appeared to harbour 6/11 alone (table 4).

The distribution of virus positive tumours according to grade, stage, and follow up is shown in table 5 . The search of possible correlations between the presence of HPV DNA in neoplastic tissue and the clinicopathological features of the disease showed that HPV DNA positive tumours were more often of grade III and of advanced stage (T2-T4) than HPV negative cases $(53 \% v 27 \%$ for grade and $77 \%$ $v 35 \%$ for stage $(\mathrm{p}<0.05)$, respectively).

Of the total of 15 patients who died of the disease during a median follow up of 72 months, 10 were virus positive $(66.6 \%$, $\mathrm{p}<0.05 v$ virus negative cases). Among the 23 patients alive and disease-free at the latest follow up, six were virus positive $(25.6 \%)$ and 17 were virus negative $(74.4 \%, \mathrm{p}<0.05)$.

Of note is the fact that in the group of 17 virus negative $\mathrm{T} 1$ superficial tumours only one patient died of the disease, whereas two of the four patients with virus positive T1 superficial tumours died.

Table 5 Relations between HPV infection and grade, stage, and follow up of cancers

\begin{tabular}{|c|c|c|c|c|c|c|c|c|c|}
\hline \multirow[b]{2}{*}{$H P V D N A$} & \multirow[b]{2}{*}{$n$} & \multicolumn{3}{|c|}{ Grade } & \multicolumn{2}{|c|}{ Stage } & \multicolumn{3}{|c|}{ Follow upt } \\
\hline & & $I$ & $I I$ & III & $T 1$ & $T 2-T 4$ & $A D F$ & $A D$ & $D D$ \\
\hline Positive & 17 & 0 & 8 & 9 & 4 & $13^{\star}$ & 6 & 1 & $10^{\star}$ \\
\hline Negative & 26 & 3 & 16 & 7 & 17 & 9 & 17 & 3 & 5 \\
\hline Total & 43 & 3 & 24 & 16 & 21 & 22 & 23 & 4 & 15 \\
\hline
\end{tabular}

†One patient lost to follow up.

$\mathrm{AD}$, alive with disease; $\mathrm{ADF}$, alive and disease-free; $\mathrm{DD}$, died of disease.

${ }^{\star} \mathrm{p}<0.05 v$ virus negative.

\section{Discussion}

The evidence linking specific HPV types with genital neoplasms, ${ }^{7}{ }^{12} 13$ together with the observation that HPV infection may involve the urinary tract, ${ }^{5}$ has prompted many studies investigating the presence of HPV in urinary tract neoplasms, with controversial conclusions.

In our present study, where we used the in situ hybridisation technique on 101 bladder cancer samples, we detected viral DNA in $39.5 \%$ of the cases. This is in line with previous studies employing either $\mathrm{PCR}^{4{ }^{14-17}}$ or in situ hybridisation. ${ }^{21-20}$ However, other similar studies have either failed to detect the virus ${ }^{8-11}$ or have identified it only sporadically in bladder cancer tissue. ${ }^{121-25}$

Our study has shown the importance of using several probes on multiple biopsies from the same case to make a positive identification of the presence of HPV in cases which otherwise might be considered negative. Indeed, the cases biopsied more than once, and also during follow up, showed a higher proportion of positive results than those with a single biopsy, though the difference did not reach statistical significance. This suggests that the virus does not infect neoplastic tissue uniformly, but that it has a focal distribution and so HPV DNA is found only when the biopsy is taken from the right place in the tumour.

In support of this, we found that the two generic broad spectrum probes, though capable of detecting a larger number of virus positive cases than type-specific probes (suggesting the presence of virus types other than those commonly known to be cancer associated), were still unable to identify all the positive cases.

Both these reasons may account for the fact that the percentage of virus infection in our series of bladder cancer samples was higher than has often reported in the past.

The use of the immunoenzymatic technique on serum samples did not prove useful in discriminating virus positive from virus negative cases, as $25 \%$ of the virus positive cancers were found in serum negative patients. Thus the presence of serum anti-HPV antibodies does not represent a reliable marker of the presence of the virus in bladder cancers, and the serological tests for HPV antibodies currently available have little clinical value.

Another finding of our present study was the observation that in 14 of the 17 infected cases the virus was either types $16 / 18$ or types $31 / 33$ / 35 , both associated with high risk of developing genital dysplasia and cancer. ${ }^{13}{ }^{26}$ Similar results have been obtained in previous studies that have investigated both low and high oncogenic risk HPV types; these have all confirmed the prevalence of high risk HPV type 16/18. ${ }^{416-18} 20$ However, in our study, the HPV types found more commonly in transitional cell bladder carcinoma were $31 / 33 / 35$, which we found in about $60 \%$ of the cases, whereas we found types $16 / 18$ in only about $24 \%$; this may help to explain the lower incidence of infection found 
by investigators who did not look specifically for this HPV group. ${ }^{27-29}$

In high grade cervical intraepithelial neoplasia, HPV types $31 / 33$ are the most common, being detected in $25 \%$ of the cases, followed by type $16 .^{26}$

As in genital cancers, the presence of HPV DNA in tumour tissue has been shown to be related to the pathological grade of the cancer and to cancer stage and patient survival. ${ }^{341726}$ In the present study we also found that the presence of virus was correlated with stage of invasion $(\mathrm{p}<0.05)$, and showed a trend towards correlation with tumour grade. These data, though not unequivocal, ${ }^{12}{ }^{219}$ suggest that HPV positive bladder cancers may behave differently from HPV negative cases. Further support for this is given by the fact that virus positive cases appeared to have a worse outcome than virus negative cases $(p<0.01)$. Thus HPV infection probably influences the clinical behaviour of bladder carcinoma in terms of tumour progression and survival. In the superficial cases, which represent the most interesting class of lesions with an unpredictable course, two of the four cases with virus positive lesions died, while only one of 17 virus negative cases with superficial lesions died.

According to Lopez-Beltran and Escudero, ${ }^{3}$ HPV infection in patients with bladder cancer is associated with high grade and high stage tumours and reduced survival, especially in immunocompromised patients. This implies that the virus favours disease progression in subjects with reduced immune defences.

Kamel et al suggested that HPV may play a role in the pathogenesis of bladder carcinomas in addition to other factors such as activation of oncogenes or inactivation of tumour suppressor genes. ${ }^{20}$ Tenti et al, studying a series of bladder cancers with and without HPV infection, concluded that virus infection was an important molecular event in the progression of papillary lesions. ${ }^{4}$

As in anogenital cancers, HPV may participate in tumour promotion or progression by binding the $\mathrm{p} 53$ and $\mathrm{Rb}$ nuclear proteins, which regulate the onset of cell proliferation and the progression of cells in the proliferative phase by means of the early E6 and E7 viral oncoproteins..$^{130}$ At present, however, it is purely speculative as to whether the relation between HPV infection and the evolution of bladder cancer is caused by a direct effect of the virus on the tumour or by the reduced resistance that follows a virus infection.

Further studies will be required to clarify the part played by HPV in bladder cancer and to confirm its role in predicting the evolution at least of a subset of bladder cancers, thus aiding the clinician in providing the most suitable treatment and follow up strategy for the individual patient.

We gratefully acknowledge the Editorial staff of $\mathcal{F}$ Clin Pathol for the careful revision of the manuscript, and technical assistance of Mrs Paola Manni and Mrs Romana Iotti. This work was supof Mrs Paola Manni and Mrs Romana Iotti. This work was sup-
ported in part by the University of Modena and by MURST ported in pata 40 .
1 Chetsanga C, Malmstrom PU, Gyllesten U, et al. Low incidence of human papillomavirus type 16 DNA in bladder tumour detected by the polymerase chain reaction. Cancer

2 Anwar K, Naiki $\mathrm{H}$, Nakakuki K, et al. High frequency of human papillomavirus infection in carcinoma of the urinary bladder. Cancer 1992;70:1267-73.

3 Lopez-Beltran A, Escudero AL. Human papillomavirus and bladder cancer. Biomed Pharmacother 1997;51:252-7.

4 Tenti P, Zappatore R, Romagnoli S, et al. p53 Overexpression and human papillomavirus infection in transitional cell carcinoma of the urinary bladder: correlation with histological parameters. F Pathol 1996;178:65-70.

5 Del Mistro A, Koss LG, Braunstein J, et al. Condyloma acuminatum of the urinary bladder: natural history, viral typing, and DNA content. Am $\mathcal{F}$ Surg Pathol 1988;12:205-15.

6 Zur Hausen H. Papillomaviruses in anogenital cancer as a Zur Hausen $\mathrm{H}$. Papillomaviruses in anogenital cancer as a
model to understand the role of viruses in human cancer. model to understand the role
Cancer Res 1989;49:4677-81.

7 Zur Hausen H. Molecular pathogenesis of cancer of the cervix and its causation by specific human papillomavirus types. Curr Top Microb Immunol 1994;186:131-56.

8 Knowles MA. Human papillomavirus sequences are not detectable by Southern blotting or general primermediated polymerase chain reaction in transitional cell tumours of the bladder. Urol Res 1992;20:297-301.

9 Salzstein DR, Orihuela E, Kocurec JN, et al. Failure of the polymerase chain reaction (PCR) to detect human papillomavirus (HPV) in transitional cell carcinoma of the bladder. Anticancer Res 1993;13:423-5.

10 Chang F, Lipponen P, Tervahauta A, et al. Transitional cell carcinoma of the bladder: failure to demonstrate human papillomavirus deoxyribonucleic acid by in situ hybridization and polymerase chain reaction. F Urol 1994;152:1429-33.

11 Sano T, Sakurai S, Fukuda T, et al. Unsuccessful effort to detect human papillomavirus DNA in urinary bladder cancers by the polymerase chain reaction and in situ cers by the polymerase chain reaction
hybridization. Pathol Int 1995;45:506-12.

12 Lancaster WD, Castellano C, Santos C, et al. Human papillomavirus deoxyribonucleic acid in cervical carcinoma from primary and metastatic sites. Am f Obstet Gynecol 1986;154:115-19.

13 O'Connor DP, Bennett MA, Murphy GM, et al. Do human papillomavirus cause cancer? Curr Diagn Pathol 1996;3:1235.

14 Song-ting Y, Ming-ming W, Li-ming L. Prevalence of human papillomaviruses 16 and 18 in transitional cell carcinoma of bladder. Chinese Med F 1993;106:494-6.

15 Agliano AM, Gradilone A, Gazzaniga P, et al. High frequency of human papillomavirus detection in urinary bladder cancer. Urol Int 1994;53:125-9.

$16 \mathrm{Kim} \mathrm{KM,} \mathrm{Kim} \mathrm{YS.} \mathrm{Analysis} \mathrm{of} \mathrm{p53} \mathrm{tumour} \mathrm{suppressor} \mathrm{gene}$ mutations and human papillomavirus infection in human mutations and human papillomavirus infectio

17 La Rue H, Simoneau M, Fradet Y. Human papillomavirus in transitional cell carcinoma of the urinary bladder. Clin Cancer Res 1995;1:435-40.

18 Lopez-Beltran A, Carrasco JC, Reymundo C, et al. Bladder cancer survival and human papillomavirus infection. Immunohistochemistry and in situ hybridization. In: Olsson CA, ed. Oncogenes and molecular genetics of urological tumours. London: Churchill Livingstone, 1992:83-9.

19 Furihata $M$, Inoue K, Otsuki Y, et al. High risk human papillomavirus infection and overexpression of $\mathrm{p} 53$ protein as prognostic indicators in transitional cell carcinoma of the urinary bladder. Cancer Res 1993;53:4823-7.

20 Kamel D, Paakko P, Pollanen R, et al. Human papillomavirus DNA and abnormal p53 expression in carcinoma of the rus DNA and abnormal p53 expression in
urinary bladder. APMIS 1995;103:331-8.

21 Kerley SW, Persons DL, Fishback JL. Human papillomavirus and carcinoma of the urinary bladder. Mod Pathol 1991;4:316-19.

22 Wilczynski SP, Oft $\mathrm{M}$, Cook N, et al. Human papillomavirus type 6 in squamous cell carcinoma of the bladder and cervix. Hum Pathol 1993;24:96-102.

23 Maloney KE, Wiener JS, Walther PJ. Oncogenic human papillomaviruses are rarely associated with squamous cell carcinoma of the bladder: evaluation by differential polymerase chain reaction. F Urol 1994;151:360-4.

24 Noel JC, Thiry L, Verhest A, et al. Transitional cell carcinoma of the bladder: evaluation of the role of human papillomaviruses. Urology 1994;44:671-5.

25 Mvula M, Iwasaka T, Iguchi A, et al. Do human papillomaMvula $M$, Iwasaka $T$, Iguchi A, et al. Do human papilloma-
viruses have a role in the pathogenesis of bladder viruses have a role in the patho
carcinoma? $\mathcal{F}$ Urol 1996;155:471-4.

26 Kalantari M, Karlsen F, Johansson B, et al. Human papillomavirus findings in relation to cervical intraepithelial neoplasia grade: a study on 476 Stockholm women, using PCR for detection and typing of HPV. Hum Pathol 1997;28:899904.

27 Bryant P, Davies P, Wilson D. Detection of human papillomavirus DNA in cancer of the urinary bladder by in situ hybridization. Br F Urol 1991;68:49-52.

28 Gopalkrishna V, Srivastava AN, Hedau S, et al. Detection of human papillomavirus in cancer of the urinary bladder by in situ hybridization and polymerase chain reaction. Genitourin Med 1995;71:231-3.

29 Lopez-Beltran A, Munoz E. Transitional cell carcinoma of the bladder: low incidence of human papillomavirus detected by the polymerase chain reaction and in situ hybridization. Histopathology 1995;26:565-9.

30 Park TW, Fujiwara H, Wright TC. Molecular biology of cervical cancer and its precursors. Cancer 1995;76: 1902-13. 